\title{
Stereoselective synthesis of C-ketosides by sequential intramolecular hydrogen atom transfer-intermolecular allylation reaction
}

\author{
Angeles Martín *, Inés Pérez-Martín, Luis M. Quintanal, Ernesto Suárez * \\ Instituto de Productos Naturales y Agrobiología del C.S.I.C., Carretera de La Esperanza 3, 38206 La Laguna, Tenerife, Spain
}

\section{a r t i c l e i n f o}

\section{Article history:}

Received 14 May 2008

Revised 9 June 2008

Accepted 16 June 2008

Available online 19 June 2008

Keywords:

C-Ketoside

Radical reaction

Hydrogen transfer

Allylation

Tandem

\section{$\mathrm{a} b \mathrm{~s} \mathrm{t} \mathrm{r}$ a $\mathrm{c} t$}

A tandem 1,5 or 1,6 hydrogen atom transfer (HAT)-radical allylation using carbohydrate models is described. The HAT reaction generated a C-glycos-1-yl radical intermediate, which added to allyltri- $n$ butyltin with high diastereoselectivity, to give C-ketosides with the quaternary carbon carrying two differently functionalized tethers.
C-Ketosides or bis-C,C-glycosides are a class of carbohydrate analogs that have received increased synthetic attention recently due to their relationship with C-glycosides of ulosonic acids ${ }^{1}$ and the detection of this unit as a recognizable substructure in many natural products with interesting biological properties. ${ }^{2}$

Anumber of synthetic procedures have been reported by several groups, ${ }^{3}$ in many cases inspired by processes developed for the preparation of the closely related and more extensively studied C-glycosides. ${ }^{4}$

However, the use of radical reactions for the synthesis of C-ketosides has, somewhat surprisingly, received very little attention, apart from a few products prepared by the reductive denitration of 1-nitro-C-glycosides with $n$ - $\mathrm{Bu}_{3} \mathrm{SnH}$ and acrylonitrile ${ }^{5}$ the reaction of sugar dihalides with allyltri- $n$-butyltin, ${ }^{6}$ and recently, through the diastereocontrolled Norrish-Yang photocyclization of 5,9-anhydro-1,4-dideoxy-deco-2,3-diuloses. ${ }^{2 b}$ Radical reactions have also been used for the synthesis of $\mathrm{C}$ - glycosides of neuraminic acids. ${ }^{7}$

We envisaged a simple methodology for the preparation of Cketosides using an intramolecular hydrogen atom transfer (HAT) reaction as the key step. A conveniently disposed alkoxyl radical would trigger the HAT reaction and the C-radical intermediate could be added to allylstannanes to give allylsubstituted products as depicted in Scheme 1. The resulting product is a C-ketoside with the quaternary carbon carrying two differently functionalized teth-

\footnotetext{
* Corresponding authors. Tel.: +34 922 251004; fax: +34 922260135 (E.S.).

E-mail addresses: angelesmartin@ipna.csic.es (A. Martín), esuarez@ipna.csic.es (E. Suárez).
}
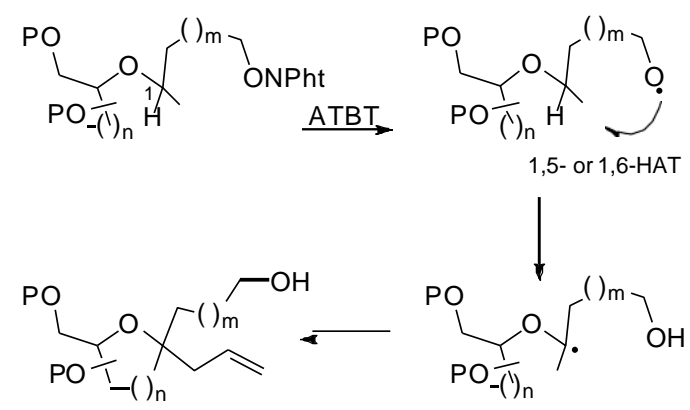

Scheme 1. $n, m=1,2 ;$ ATBT = allyltri- $n$-butyltin; Pht = phthalimide.

ers. The diastereoselectivity at the pseudoanomeric center may be controlled by two stereoelectronic effects: the radical anomeric effect and the quasi-homo-anomeric effect. ${ }^{8}$

Remote free radical functionalization on inactivated carbons via HAT reactions has attracted considerable interest among synthetic organic chemists. ${ }^{9}$ The reaction, when promoted by alkoxyl radicals, occurs most frequently through a six-membered transition state (TS). ${ }^{10}$ Some exceptional cases are known of 1,6 -HAT reactions that proceed, generally in low yield, via a seven-membered TS; only when the hydrogen atom to be removed is bonded to an oxygen-substituted carbon atom can the yield be considered to be of synthetic interest and in some cases even competes favorably with the 1,5-process. ${ }^{11}$

To the best of our knowledge, the tandem intramolecular HATintermolecular allylation reaction proposed in Scheme 1 has never 
been described. However, examples are known of sequential alkoxyl radical promoted HAT and subsequent addition of the Cradical intermediate to electron-deficient olefins. ${ }^{12}$ Despite its potential usefulness, this methodology has not been widely employed, probably because of the difficulties encountered in the preparation of alkoxyl radicals under non-oxidative conditions. ${ }^{13}$

We have used the fragmentation of $N$-hydroxyphthalimide derivatives to generate the alkoxyl radicals and allyltri- $n$-butyltin as a radical trap in the conditions summarized in Table $1 .{ }^{14}$

The alditol precursors of phthalimides $1,3,4$, and 6 were obtained by reaction of 2,3,4,6-tetra-O-methyl-D-mannopyranosyl chloride with butenylmagnesium bromide. The resulting dec-1enitol was submitted to ozonolysis to give the three-carbon tethers or to hydroboration to afford the four-carbon tether alcohols. While the alditol precursors of phthalimides 7 and 9, possessing a three-carbon tether, were synthesized by $\mathrm{C}$-glycosidation of the corresponding saccharide with allyltrimethylsilane $/ \mathrm{BF}_{3} \cdot \mathrm{Et}_{2} \mathrm{O}$ and subsequent hydroboration of the terminal olefin. ${ }^{4 j}$ The stable $\mathrm{N}$ hydroxyphthalimido derivatives were prepared by reaction of the respective alcohols with $\mathrm{N}$-hydroxyphthalimide under Mitsunobu conditions. ${ }^{15}$

The thermally initiated reaction of the isomeric phthalimides 1 and 3 with allyltri- $n$-butyltin/AIBN gave exclusively the C-ketoside 2 (entries 1 and 2). ${ }^{16}$ This compound was seemingly obtained as a single diastereoisomer within the detection limits of ${ }^{1} \mathrm{H}$ and ${ }^{13} \mathrm{C}$ NMR spectroscopy, by the analysis of the crude reaction mixtures.

Table 1

Sequential intramolecular HAT-intermolecular allylation reaction ${ }^{a}$

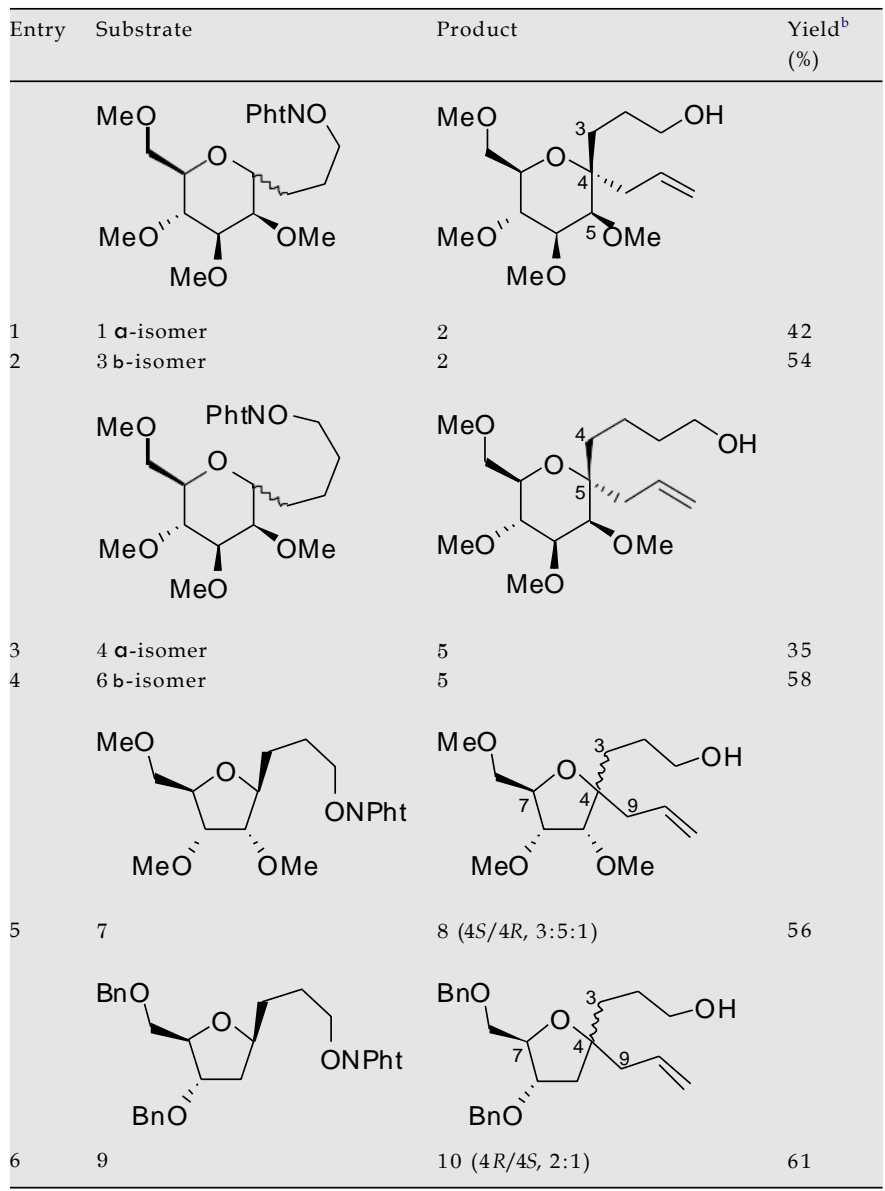

${ }^{a}$ A solution of the corresponding phthalimide-derivative $(1 \mathrm{mmol})$ in dry ben zene $(10 \mathrm{~mL})$ was treated with allyltri- $n$-butyltin $(10 \mathrm{mmol})$ and AIBN $(0.01 \mathrm{mmol})$ under reflux.

${ }^{b}$ The reduced starting alcohol was always also obtained (5-28\%), see Supplementary data.

The stereochemistry at the quaternary center was tentatively assigned as $R$ on the basis of the NOE interaction observed between $\mathrm{H}-3$ and the methoxy group at C-5. ${ }^{17}$ It will be noted that, as expected, radical a-axial attack operates regardless of the stereochemistry at the pseudoanomeric center in the starting phthalimide. ${ }^{18}$ Since electrophilic radicals abstract axial hydrogens very much faster than the equatorial ones, it is not very surprising that the reaction of the $b$-isomer 3 gave somewhat better results (entry 2). ${ }^{19}$

The reaction can also be extended to isomers 4 and 6 where a four-carbon tether would require a HAT through a seven-membered TS. The reaction proceeded in a similar manner to that of the previous case; once again only the $R$ diastereomer 5 formed by radical quenching along the a-axial direction could be detected and also the b-isomer 6 gave the best yield (entries 3 and 4 ). The low yield obtained with the a-isomer deserves a brief comment. In a previous work from this laboratory, the reaction of phthalimide 4 with $n$ - $\mathrm{Bu}_{3} \mathrm{SnH} / \mathrm{AIBN}$ was studied in some detail, two products being obtained: the inverted alcohol $11(40 \%)$ and alcohol 12 $(59 \%)$ where the configuration at C-5 has apparently been retained (Scheme 2). ${ }^{20}$ An experiment with $n-\mathrm{Bu}_{3} \mathrm{SnD} / \mathrm{AIBN}$ gave compounds $13(32 \%)$ and $14(61 \%)$; the incorporation of deuterium at C-4 in the latter indicates that the 1,6-HAT reaction suffers from competing 1,5-HAT with hydrogen abstraction at C-4. This is also observed in the reaction with allyltri- $n$-butyltin where apart from 5 the C-4 allylated compound 15 is obtained, albeit in low yield and poor diastereoselectivity.

Interestingly, in the b-isomer 6 with the C-5 abstractable hydrogen in axial position the intramolecular functionalization proceeded exclusively by an a priori less favorable 1,6-HAT reaction. On the contrary, both 1,5- and 1,6-HAT processes compete in the a-isomer 4 since abstraction of the equatorial hydrogen at C-5 is slower.

This methodology can also be extended to the synthesis of Cketosides derived from furanosyl radicals where, contrary to observations in the case of pyranosyl radicals, steric effects seem to control the stereoselectivity. ${ }^{8 c, d, 21}$ The reaction of phthalimide 7, derived from D-ribose, afforded C-ketoside 8 (56\%) with good diastereoselectivity (3.5:1) (entry 5). Apparently, the allyl radical attack occurs preferentially by the less hindered $b$-face of the tetrahydrofuran ring. The presence of NOE interactions between

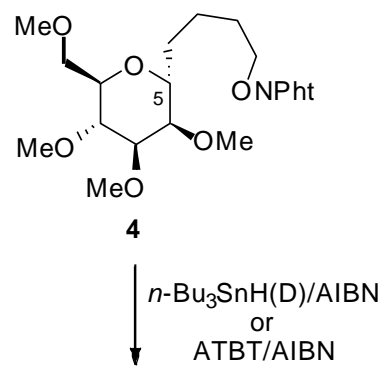

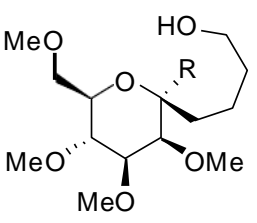

$$
\begin{aligned}
11 R & =H 40 \% \\
13 R & =D 32 \% \\
5 R & =\text { allyl } 35 \%
\end{aligned}
$$

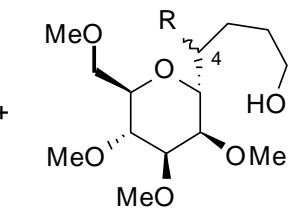

$12 \mathrm{R}=\mathrm{H} 59 \%$

$14 \mathrm{R}=\mathrm{D}(\mathrm{H})(4: 1) 61 \%$

$15 \mathrm{R}=$ allyl (1.5:1) 4\% 
H-9 and H-5, H-9 and H-6, and H-3 and H-7 in the major isomer seems to be in agreement with the proposed $4 S$ stereochemistry. ${ }^{22}$

With less sterically demanding substrates, the reaction leads to products with poorer diastereoselectivity, and such is the case of 5deoxy-phthalimide 9 which afforded C-ketoside 10 (2:1) (entry 6). The absence of a substituent at $\mathrm{C}-5$ suffices to reverse the sense of the stereoselectivity and now the attack on the a-face of the ring thus becomes favorable. A NOE interaction between H-9 and H-7 supports the $4 R$ stereochemistry for the major isomer. ${ }^{22}$

In summary, this procedure provides a simple stereocontrolled methodology for the synthesis of a new type of C-ketosides which may be useful as scaffolds and synthetic building blocks. The two differently functionalized tethers with versatile and flexible functional groups provide suitable handles for further synthetic transformations. Extension of this chemistry in this direction is currently underway in our laboratory.

\section{Acknowledgments}

This work was supported by the Investigation Programmes nos. CTQ2007-67492 and CTQ2004-02367 of the Ministerio de Educación y Ciencia, Spain, cofinanced by the Fondo Europeo de Desarrollo Regional (FEDER). I.P.-M. and L.M.Q. thank the Program I3PCSIC, for fellowships.

\section{Supplementary data}

Supplementary data (experimental procedures and analytical data for all new compounds) associated with this article can be found, in the online version, at doi:10.1016/j.tetlet.2008.06.070.

\section{References and notes}

1. (a) Baytas, S. N.; Wang, Q.; Karst, N. A.; Dordick, J. S.; Linhardt, R. J. J. Org. Chem. 2004, 69, 6900-6903; (b) Ohnishi, Y.; Ichikawa, Y. Bioorg. Med. Chem. Lett. 2002, 12,997-999; (c) Khodair, A. I.; Schmidt, R. R. Carbohydr. Res. 2002, 337, 19671978; (d) Dondoni, A.; Giovannini, P. P.; Marra, A. J. Chem. Soc., Perkin Trans. 1 2001, 19, 2380-2388; (e) Dondoni, A.; Mariotti, G.; Marra, A.; Massi, A. Synthesis 2001, 14, 2129-2137; (f) Notz, W.; Hartel, C.; Waldscheck, B.; Schmidt, R. R. J. Org. Chem. 2001, 66, 4250-4260; (g) Poveda, A.; Asensio, J. L.; Polat, T.; Bazin, H.; Linhardt, R. J.; Jimenez-Barbero, J. Eur. J. Org. Chem. 2000 , 1805-1814; (h) Wang, Q.; Wolff, M.; Polat, T.; Du, Y.; Linhardt, R. J. Bioorg. Med. Chem. Lett. 2000, 10, 941-944; (i) Koketsu, M.; Kuberan, B.; Linhardt, R. J. Org. Lett. 2000, 2, 3361-3363; (j) Bazin, H. G.; Du, Y.; Polat, T.; Linhardt, R. J. J. Org. Chem. 1999, 64, 7254-7259; (k) Kuribayashi, T.; Mizuno, Y.; Gohya, S.; Satoh,S. I. Carbohydr. Chem. 1999, 18, 371-382; (l) Dondoni, A.; Marra, A. Chem. Commun. 1998, 16, 1741-1742; (m) Du, Y.; Polat, T.; Linhardt, R. J. Tetrahedron Lett. 1998, 39, 5007-5010; (n) Du, Y.; Linhardt, R. J. Carbohydr. Res. 1998, 308, 161-164; Wallimann, K.; Vasella, A. Helv. Chim. Acta 1991, 74, 1520-1532; (o) Crich, D.; Lim, L. B. L. Tetrahedron Lett. 1990, 31, 1897-1900.

2. For reviews on natural products, see for example: (a) Nakata, T. Chem. Rev. 2005, 105, 4314-4347; (b) Yasumoto, T.; Murata, M. Chem. Rev. 1993, 93, 1897 1909. For the synthesis of C-ketosides as chiral synthons, see: (c) Johnson, H. W. B.; Majumder, U.; Rainier, J. D. J. Am. Chem. Soc. 2005, 127, 848-849; (d) Allwein, S. P.; Cox, J. M.; Howard, B. E.; Johnson, H. W. B.; Rainier, J. D. Tetrahedron 2002, 58, 1997-2009; (e) Nicolaou, K. C.; Bunnage, M. E.; McGarry, D. G.; Shi, S.; Somers, P. K.; Wallace, P. A.; Chu, X.-J.; Agrios, K. A.; Gunzner, J. L.; Yang, Z. Chem. Eur. J. 1999, 5, 599-617; (f) Oishi, T.; Naguno, Y.; Hirama, M. Chem. Commun. 1998, 1041-1042; (g) Suh, H.; Wilcox, C. S. J. Am. Chem. Soc. $1988,110,470-481$.

3. For a detailed list of procedures to generate C-ketosides prior to 2004, see: (a) Roberts, S. W.; Rainier, J. D. Org. Lett. 2005, 7, 1141-1144. For more recent references, see: (b) Herrera, A. J.; Rondon, M.; Suarez, E. Synlett 2007, 18511856; (c) Malapelle, A.; Coslovi, A.; Doisneau, G.; Beau, J. M. Eur. J. Org. Chem. 2007, 3145-3157; (d) Gomez, A. M.; Uriel, C.; Valverde, S.; Lopez, J. C. Org. Lett. 2006, 8, 3187-3190; (e) Majumder, U.; Cox, J. M.; Johnson, H. W. B.; Rainier, J. D. Chem. Eur. J. 2006, 12, 1736-1746; (f) Schweizer, F.; Hindsgaul, O. Carbohydr. Res. 2006, 341, 1730-1736; (g) Zhang, K. D.; Schweizer, F. Synlett 2005, 31113115; (h) Lavrenov, S. N.; Solovyeva, N. P.; Reznikova, M. I.; Anisimova, O. S.; Preobrazhenskaya, M. N. Nucleosides, Nucleotides Nucleic Acids 2004, 23, 281289.

4. Reviews on C-glycosides: (a) Wellington, K. W.; Benner, S. A. Nucleosides Nucleotides Nucleic Acids 2006, 25, 1309-1333; (b) Bililign, T.; Griffith, B. R.;
Thorson, J. S. Nat. Prod. Rep. 2005, 22, 742-760; (c) Lee, D. Y. W.; He, M. S. Curr. Top. Med. Chem. 2005, 5, 1333-1350; (d) Dondoni, A.; Marra, A. Chem. Rev. 2000, 100, 4395-4421; (e) Vogel, P.; Ferritto, R.; Kraehenbuehl, K.; Baudat, A. In Carbohydrate Mimics: Concepts and Methods; Chapleur, Y., Ed.; Chemie: Weinheim, 1998. Chapter 2, pp 19-48; (f) Togo, H.; He, W.; Waki, Y.; Yokoyama, M. Synlett 1998, 700-717; (g) Du, Y. G.; Linhardt, R. J.; Vlahov, I. R. Tetrahedron 1998, 54, 9913-9959; (h) Beau, J. M.; Gallagher, T. Top. Curr. Chem. 1997, 187, 1-54; (i) Nicotra, F. Top. Curr. Chem. 1997, 187, 55-83; (j) Levy, D. E.; Tang, C. The Chemistry of C-Glycosides; Elsevier: Cambridge, 1995; (k) Postema, M. H. D. Tetrahedron 1992, 48, 8545-8599.

5. (a) Giese, B.; Dupuis, J.; Leising, M.; Nix, M.; Lindner, H. J. Carbohydr. Res. 1987, 171, 329-341; (b) Dupuis, J.; Giese, B.; Hartung, J.; Leising, M.; Korth, H.-G.; Sustmann, R. J.Am. Chem. Soc. 1985, 107, 4332-4333.

6. Chen, G.-R.; Fei, Z. B.; Huang, X.-T.; Xie, Y.-Y.; Xu, J.-L.; Gola, J.; Steng, M.; Pral, J.-P. Eur. J. Org. Chem 2001, 2939-2946.

7. (a) Wang, Q.; Linhardt, R. J. J. Org. Chem. 2003, 68, 2668-2672; (b) Polat, T.; Du, Y.; Linhardt, R. J. Synlett 1998, 1195-1196; (c) Vlahov, I. R.; Vlahov, P. I.; Linhardt, R. J. J. Am. Chem. Soc. 1997, 119, 1480-1481; (d) Paulsen, H.; Matschulat, P. Liebigs Ann. Chem. 1991, 487-495; (e) Nagy, J. O.; Bernadsky, M. D. Tetrahedron Lett. 1991, 32, 3953-3956.

8. (a) Beckwith, A. L. J.; Duggan, P. J. Tetrahedron 1998, 54, 4623-4632; (b) Beckwith, A. L. J.; Duggan, P. J. Tetrahedron 1998, 54, 6919-6928; (c) Curran, D. P.; Porter, N. A.; Giese, B. Stereochemistry of Radical Reactions; VCH: Weinheim, 1995; (d) Giese, B. Angew. Chem., Int. Ed. Engl. 1989, 28, 969-980; (e) Korth, H.G.; Sustmann, R.; Dupuis, J.; Giese, B. J. Chem. Soc., Perkin Trans. 2 1986, 1453 1459; (f) Barton, D. H. R.; Hartwig, W.; Motherwell, W. B. J. Chem. Soc., Chem. Commun. 1982, 4397-4410.

9. (a) Cekovic, Z. J. Serb. Chem. Soc. 2005, 70, 287-318; (b) Feray, L.; Kuznetsov, N.; Renaud, P. In Radicals in Organic Synthesis; Renaud, P., Sibi, M. P., Eds.; WileyVCH: Weinheim, 2001; Vol. 2, pp 246-278; (c) Robertson, J.; Pillai, J.; Lush, R. K. Chem. Soc. Rev. 2001, 30, 94-103; (d) Majetich, G. Tetrahedron 1995, 51, 70957129 .

10. (a) Dorigo, A. E.; McCarrick, M. A.; Loncharich, R. J.; Houk, K. N. J. Am. Chem. Soc. 1990, 112, 7508-7514; (b) Dorigo, A. E.; Houk, K. N. J. Am. Chem. Soc. 1987, 109, 2195-2197.

11. (a) Dorta, R. L.; Martín, A.; Salazar, J. A.; Suárez, E.; Prangé, T. J. Org. Chem. 1998, 63, 2251-2261; (b) Martín, A.; Salazar, J. A.; Suárez, E. J. Org. Chem. 1996, 61, 3999-4006; (c) Danishefsky, S. J.; Armistead, D. M.; Wincott, F. E.; Selnick, H. G.; Hungate, R. J. Am. Chem. Soc. 1987, 109, 8117-8119; (d) Kay, I. T.; Bartholomew, D. Tetrahedron Lett. 1984, 25, 2035-2038; (e) Concepción, J. I.; Francisco, C. G.; Hernández, R.; Salazar, J. A.; Suárez, E. Tetrahedron Lett. 1984, 25, 1953-1956; (f) Brun, P.; Waegell, B. In Reactive Intermediates; Abramovitch, R. A., Ed.; Plenum Press: New York, 1983; Vol. 3, pp 367-426.

12. (a) Petrovic, G.; Cekovic, Z. Synthesis 2004, 1671-1679; (b) Petrovic, G.; Cekovic, Z. Org. Lett. 2000, 2, 3769-3772; (c) Petrovic, G.; Cekovic, Z. Tetrahedron 1999, 55, 1377-1390; (d) Petrovic, G.; Cekovic, Z. Tetrahedron Lett. 1997, 38, 627-630; (e) Cekovic, Z.; Ilijev, D. Tetrahedron Lett. 1988, 29, 1441-1444.

13. For a review on oxygen-centered radicals, see: Hartung, J.; Gottwald, T.; Spehar, K. Synthesis 2002, 1469-1498.

14. (a) Kim, S.; Lee, T. A.; Song, Y. Synlett 1998, 471-472; (b) Okada, K.; Okamoto, K.; Oda, M. J. Am. Chem. Soc. 1988, 110, 8736-8738; (c) Okada, K.; Okamoto, K.; Oda, M. J. Chem. Soc., Chem. Commun. 1989, 1636-1637; (d) Barton, D. H. R.; Blundell, P.; Jaszberenyi, J. Cs. Tetrahedron Lett. 1989, 30, 2341-2344; (e) Crich, D.; Huang, X.; Newcomb, M. J. Org. Chem. 2000, 65, 523-529; (f) Crich, D.; Huang, X.; Newcomb, M. Org. Lett. 1999, 1, 225-227.

15. (a) Mitsunobu, O. Synthesis 1981,1-28; (b) Grochowski, E.; Jurczak, J. Synthesis $1976,682-684$.

16. A similar moderate yield was obtained in the related addition of glucopyranosyl radical to acrylonitrile: Giese, B.; Dupuis, J.; Nix, M. Org. Synth. $1987,65,236-242$.

17. The methoxy group at C-5 can be easily distinguished by 2D-HSQC and HMBC correlations.

18. Praly, J.-P. Tetrahedron Lett. 1983, 24, 3075-3078; Giese, B.; Dupuis, J. Tetrahedron Lett. 1984, 25, 1349-1352; Brunckova, J.; Crich, D.; Yao, Q. Tetrahedron Lett. 1994, 35, 6619-6622; Yamazaki, N.; Eichenberger, E.; Curran, D. P. Tetrahedron Lett. 1994, 35, 6623-6626; Crich, D.; Sun, S.; Brunckova, J. J. Org. Chem. 1996, 61, 605-615.

19. (a) Hayday, K.; McKelvey, R. D. J. Org. Chem. 1976, 41, 2222-2226; (b) Beckwith, A. L. J.; Easton, C. J. J. Am. Chem. Soc. 1981, 103, 615-619; (c) Beckwith, A. L. J.; Brumby, S. J. Chem. Soc., Perkin Trans. 2 1987, 1801-1807.

20. Martín, A.; Quintanal, L. M.; Suárez, E. Tetrahedron Lett. 2007, 48, 5507- 5511.

21. Araki, Y.; Endo, T.; Tanji, M.; Nagasawa, J.; Ishido, Y. Tetrahedron Lett. 1988, 29, 351-354.

22. A word of caution should be given in regard to the C-4 stereochemistry of 8 and 10. The chromatographic separation of these diastereoisomeric mixtures proved impossible even after derivatization of the primary alcohol. In consequence, the C-4 stereochemistry has only been tentatively assigned on the basis of NOESY experiments of the major isomer in the mixture spectra. Nevertheless, the results shown in Table 1 are consistent with the steric effects previously observed for furanosyl radical additions, see Refs. 8c, 8d, 21. 